\title{
Aspectos biológicos da Traça-da-Batatinha Phthorimaea operculella (Zeller) (Lepidoptera: Gelechiidae)
}

\author{
Biologic Aspects of Phthorimaea operculella (Zeller) (Lepidoptera: Gelechiidae)
}

\author{
Dirceu Pratissoli ${ }^{1}$ José Roberto Postali Parra ${ }^{2}$ \\ Harley Nonato de Oliveira ${ }^{3}$ Fabricio Fagundes Pereira ${ }^{4}$
}

\section{RESUMO}

Algumas características biológicas de Phthorimaea operculella (Zeller) (Lepidoptera: Gelechiidae) criadas em tubérculos de batata, foram estudadas em laboratório a $25 \pm$ $1{ }^{\circ} \mathrm{C}, 70 \pm 10 \%$ de umidade relativa e fotofase de 14 horas. $A$ longevidade dos machos foi de 33,4 dias e das fêmeas foi de 31,7 dias, a sobrevivência foi de $100 \%$ até o sexto dia para ambos os sexos, e o número médio total de ovos por fêmea de $\boldsymbol{P}$. operculella foi 195, com viabilidade de 46,3\%, quando esses foram alimentados com solução de mel a $10 \%$.

Palavras-chave: biologia, praga, batata.

\section{ABSTRACT}

Some biologic characteristics of Phthorimaea operculella (Zeller) (Lepidoptera: Gelechiidae) reared in potato tubers was studied in laboratory at $25 \pm 1{ }^{\circ} \mathrm{C}$, relative humidity of $70 \pm 10 \%$ and photophase of 14 hours. The male longevity it was 33.4 days and the female longevity it was 31.4 days, the survivor it was $100 \%$ until the 6o day for both sex, the total number of eggs per female of $\boldsymbol{P}$. operculella it was 195 , with viability of $46.3 \%$, when these adults received a solution of honey at $10 \%$.

Key words: biology, pest, potato.
Phthorimaea operculella (Zeller) (Lepidoptera: Gelechiidae), conhecida vulgarmente como traça-da-batatinha, é um inseto oligófago, hospedeiro de solanáceas e uma das principais pragas da batata (Solanum tuberosum) (VON ARX et al., 1990; ZUCCHI et al., 1993). Suas lagartas têm de 10 a $12 \mathrm{~mm}$ de comprimento, são branco-esverdeadas no início e branco-amareladas no final do desenvolvimento, com cabeça marron. As pupas são marron-avermelhada sendo geralmente protegidas por um casulo de teia, fora da galeria do tubérculo. Os adultos possuem $15 \mathrm{~mm}$ de envergadura, coloração cinza e asas franjadas. A asa anterior é cinza mais escura com alguns pontos pretos irregulares (ZUCCHI et al., 1993).

Essa praga ocorre em todas as épocas de plantio da batata, provocando o secamento e a destruição dos tubérculos tanto no campo quanto no armazenamento (ZUCCHI et al., 1993). Suas larvas produzem um dano característico nas folhas, caule e tubérculos, formando galerias nas folhas ao consumir o parênquima, dano típico de um minador, brocando o caule e perfurando os tubérculos, geralmente pelas

${ }^{1}$ Engenheiro Agrônomo, Professor Doutor Entomologia, Centro de Ciências Agrárias da Universidade Federal do Espírito Santo (CCAUFES), 29500-000, Alegre, ES. E-mail: dirceu@npd.ufes.br Autor para correspondência.

${ }^{2}$ Engenheiro Agrônomo, Professor Doutor Entomologia, ESALQ/USP, Departamento de Entomologia, Fitopatologia e Zoologia Agrícola, CP 09, 13418-900, Piracicaba, SP.

${ }^{3}$ Engenheiro Agrônomo, Doutor Entomologia, Bolsista PROFIX do CNPq Brasil, Centro de Ciências Agrárias da Universidade Federal do Espírito Santo (CCAUFES), 29500-000, Alegre, ES.

${ }^{4}$ Engenheiro Agrônomo, Mestrando em Fitossanidade/Entomologia, Universidade Federal Rural de Pernambuco, Av. Dom Manuel de Medeiros, s/no, Bairro Dois Irmãos, 52171-900, Recife, PE. 
gemas ou olhos, ocasionando galerias em seu interior (GAMBOA \& NOTZ, 1990).

O conhecimento de aspectos biológicos é importante para o controle de $\boldsymbol{P}$. operculella, no entanto, GAMBOA \& NOTZ (1990) e VAN VUUREN et al. (1998) relataram que muitos estudos realizados com essa praga fornecem informações contraditórias, o que pode dificultar seu controle. Assim, o presente trabalho visou determinar algumas características biológicas desse lepidóptero, o que poderá auxiliar no controle dessa praga. Foram avaliados a longevidade de fêmeas e machos de P. operculella, a porcentagem de sobrevivência, o número total de ovos, o número de ovos por fêmea e a viabilidade dos ovos.

Lagartas recém eclodidas de $\boldsymbol{P}$. operculella foram obtidas do laboratório de Biologia, do Departamento de Entomologia, Fitopatologia e Zoologia Agrícola da ESALQ/ USP. Essas foram transferidas para tubérculos de batata perfurados, os quais foram dispostos em caixas de plásticas de 51,0 x 28,0 x 12,0cm, contendo no fundo, areia esterilizada, a qual serviu de substrato para pupação . Inicialmente, os tubérculos foram pesados para se conhecer o número exato de lagartas a serem inoculadas, utilizando-se duas gramas de batata para cada lagarta (PRATISSOLI et al., 1993). As lagartas permaneceram alimentando-se dos tubérculos por um período de 20 dias, quando se transformaram em pupas. Essas foram retiradas diariamente através do peneiramento da areia, sexadas, e, mantidas em tubos de 8,5 $\mathrm{x} 2,5 \mathrm{~cm}$.

Trinta casais de mariposas recém emergidas foram transferidos para gaiolas confeccionadas de tubos de PVC com $10 \mathrm{~cm}$ de diâmetro por 12 de comprimento. A extremidade superior do tubo foi fechado com tecido (filó) de malha fina afixada com elástico. Sobre o tecido colocou-se um disco de papel filtro com um pedaço de batata para estimular a postura. A extremidade inferior foi fechada com um pedaço de papelão furado no centro, por onde foi introduzido um frasco contendo solução de mel a $10 \%$. Para que os insetos pudessem se alimentar, introduziu-se um rolo dental no frasco, que ficou embebido na solução, permitindo o deslocamento do líquido por capilaridade. Diariamente, até o 25응 dia após o acasalamento, os discos de papel de filtro, contendo as posturas foram trocados e mantidos em placas de Petri $(15,0 \times 2,0 \mathrm{~cm})$, até a eclosão das lagartas. Os estudos foram realizados a $25 \pm 1{ }^{\circ} \mathrm{C}, 70 \pm 10 \%$ de umidade relativa e fotofase de 14 horas.

A longevidade dos machos foi maior que a das fêmeas, com 33,4 e 31,7 dias, respectivamente. Essa maior longevidade para machos também foi relatada por DORESTES \& NIEVES (1968), que relataram uma maior longevidade para adultos machos, quando mantidos em batata (14,4 para machos e 13,5 dias para fêmeas) e em folhas de tabaco (14,8 para machos e 9,1 dias para fêmeas) e por GAMBOA \& NOTZ (1990), que também mostraram maior longevidade para machos (24,2 dias) do que para fêmeas (17,3 dias) em batata. No entanto, a longevidade de $\boldsymbol{P}$. operculella relatada por esses autores foi sempre menor do que a encontrada no presente trabalho.

A porcentagem de sobrevivência (Figura 1A) mostrou que até o 6 ㅇa diás o acasalamento, não ocorreu mortalidade de fêmeas e até o $10^{\circ}$ dia não ocorreu mortalidade de machos. Até o 12 após o acasalamento, $68,9 \%$ da postura dos ovos foi realizada, sendo que as maiores porcentagens foram entre o $2^{\circ}$ e o 5o dia (Figura 1B). Valores semelhantes também foram relatados por FENEMORE (1977), segundo o qual o pico de oviposição de $\boldsymbol{P}$. operculella em batata foi entre 2 e o $5^{\circ}$ dia após a emergência e por GAMBOA \& NOTZ (1990), que relataram que cerca de $90,0 \%$ da postura dos ovos foram realizadas nos primeiros seis dias do período de oviposição.

O número médio total de ovos por fêmea de $\boldsymbol{P}$. operculella foi de 195, com uma viabilidade média de $46,3 \%$. Esse número de ovos por fêmea é superior aos relatados por DORESTES \& NIEVES (1968) em batata, folhas de tabaco e de tomate, que foram de 25,4, 38,8 e 50,7 respectivamente, ao encontrado por NEUPANE (1977) em batata, de 52 ovos por fêmea e por GAMBOA \& NOTZ (1990) também em batata, e que foi de 72,8 ovos por fêmea de P. operculella.

Esses resultados encontrados auxiliam na utilização de outras táticas de controle no manejo integrado dessa praga na cultura da batata. Conhecer a longevidade dos adultos e o período de maior postura, fornece informações pertinentes para a utilização de inimigos naturais como por exemplo, os do gênero Trichogramma. 


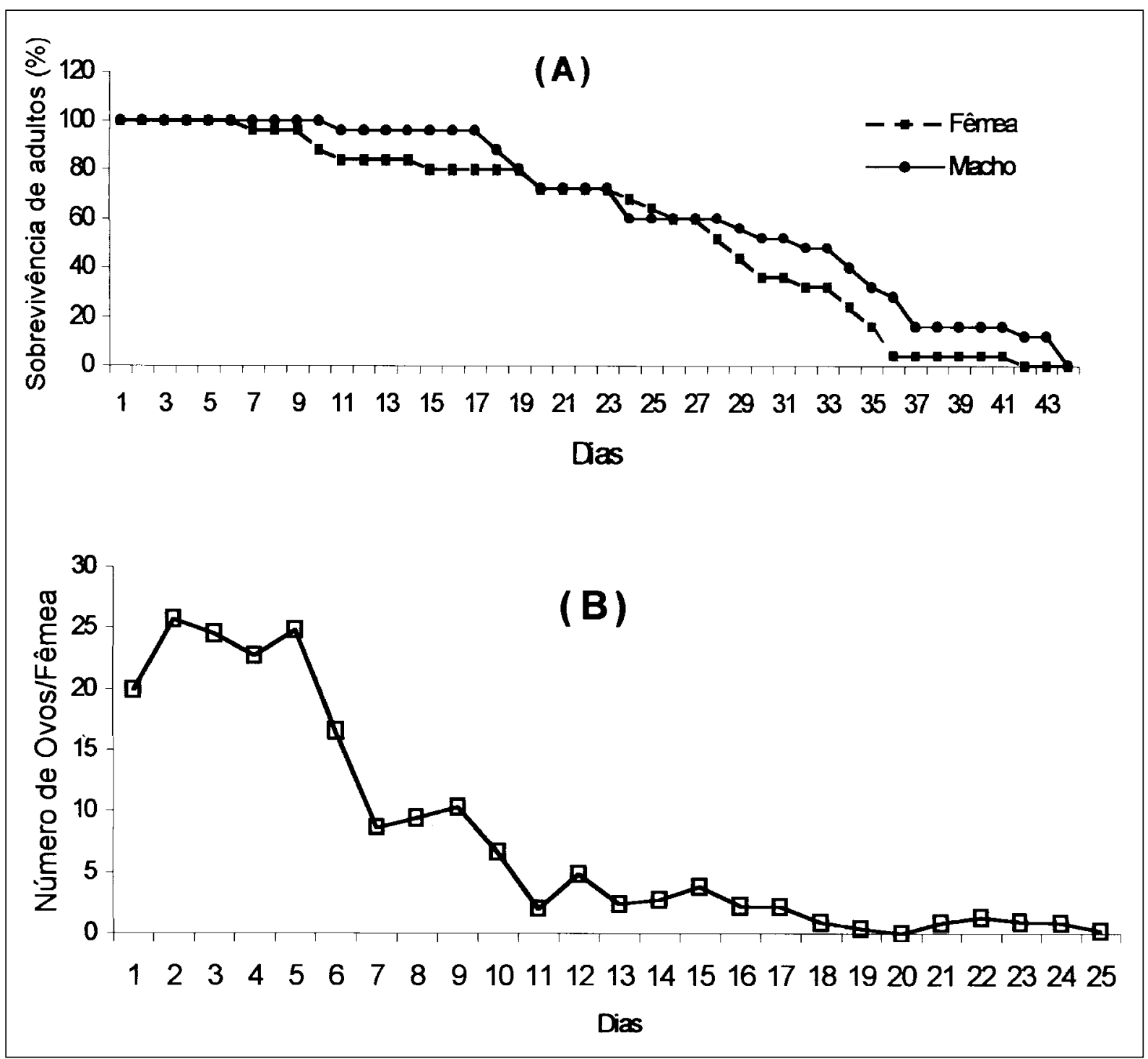

Figura 1 - (A) Porcentagem de sobrevivência de adultos de Phthorimaea operculella, criados em laboratório a $25 \pm 1{ }^{\circ} \mathrm{C}, 60 \pm 10 \%$ de umidade relativa e fotofase de 14 horas. ( B ) Número de ovos/fêmea de Phthorimaea operculella, criados em laboratório a 25 $\pm 1^{\circ} \mathrm{C}, 60 \pm 10 \%$ de umidade relativa e fotofase de 14 horas.

\section{REFERÊNCIAS BIBLIOGRÁFICAS}

DORESTES, E.; NIEVES, M. Estudio de laboratorio sobre el ciclo biológico del minador de la hoja del tabaco, papa y tomate Gnorismoschema operculella (Zeller). Agronomia Tropical, v.18, n.4, p.461-474, 1968.

FENEMORE, P.G. Oviposition of potato tuber moth, Phthorimaea operculella Zell. (Lepidoptera: Gelechiidae); fecundity in relation to mated state, age, and pupal weight. New Zealand Journal of Zoology, v.4, n.2, p.187-191, 1977.

GAMBOA, M.; NOTZ, A. Biologia de Phthorimaea operculella (Zeller) (Lepidoptera: Gelechiidae) en papa (Solanum tuberosum). Revista Faculdade Agronomia Maracay, v.16, p.219-230, 1990.

NEUPANE, F. P. S ome obervation on the biology of potato tubermoth, Phthorimaea (Gnorimoschema) operculella Zeller. Nepalese J Agric, v.12, p.159-166, 1977.

PRATISSOLI, D. et al. Aprimoramento da técnica de criação de Phthorimaea operculella (Zeller, 1873) visando ao seu controle biológico: Determinação do número ideal de lagartas por tubérculo de batata para máxima produção de insetos. In: REUNIÃO PAULISTA DE INICIAÇÃO CIENTÍFICA EM CIÊNCIAS AGRÁRIAS, 4., Piracicaba, 1993. Resumos... Piracicaba : FEALQ, 1993. p.43.

VAN VUUREN, J.J.; BENNETT, A.; BENNETT, A.L. Oviposition site preferences of potato tuber moth, Phthorimaea operculella

Ciência Rural, v. 33, n. 6, nov-dez, 2003. 
(Zeller) (Lepidoptera: Gelechiidae), a pest on tobacco, Nicotiana tabacum L. (Solanaceae). African Entomology, v.6, n.2, p.177-183, 1998.

VON ARX.; R, ROUX, O.; BAUMGARTNER, J. Tuber infestation by potato tuber moth, Phthorimaea operculella (Zeller), at potato harvest in relation to farmers' practices.
Agriculture Ecosystems and Environment, v. 31, p. 277292, 1990

ZUCCHI, R.A.; SILVEIRA NETO, S.; NAKANO, O. Guia de identificação de pragas agrícolas. Piracicaba : FEALQ, 1993. 139p.

Ciência Rural, v. 33, n. 6, nov-dez, 2003. 